\title{
The differential effects of the timing of maternal nutrient restriction in the ovine placenta on glucocorticoid sensitivity, uncoupling protein 2, peroxisome proliferator-activated receptor- $\gamma$ and cell proliferation
}

\author{
M Yiallourides, S P Sebert, V Wilson, D Sharkey, S M Rhind ${ }^{1}$, M E Symonds and H Budge \\ Early Life Nutrition Research Unit, Academic Child Health, School of Clinical Sciences, University Hospital, \\ Nottingham NG7 2UH, UK and ${ }^{1}$ Macaulay Institute, Craigiebuckler, Aberdeen AB15 8QH, UK \\ Correspondence should be addressed to M E Symonds; Email: michael.symonds@nottingham.ac.uk
}

\begin{abstract}
Nutrient restriction (NR) during critical windows of pregnancy has differential effects on placento-fetal growth and development. Our study, therefore, investigated developmental and metabolic adaptations within the ovine placenta following NR at different critical windows during the first 110 days of gestation (term $=147$ days). Thus, the effects of NR on cell proliferation, glucocorticoid sensitivity, IGF1 and 2 receptor, peroxisome proliferator-activated receptor $\gamma(P P A R G)$, and uncoupling protein (UCP)2 gene expression in the placenta were examined. Singleton bearing sheep ( $n=4-8$ per group) were fed either $100 \%$ of their total metabolizable energy requirements throughout the study or $50 \%$ of this amount between $0-30,31-65,66-110$, and $0-110$ days gestation. A significant reduction in cell proliferation and increased gene expression for the glucocorticoid and IGF2 receptors, PPARG, and UCP2 were detected in placentae sampled from mothers who were nutrient restricted between days 66 and 110 of gestation, only, relative to controls. This window of gestation coincides with the maximum placental growth and the start of exponential growth of the fetus when there are substantially increased metabolic demands on the placenta compared with earlier in gestation. Consequently, increased glucocorticoid sensitivity and suppressed IGF2 action could contribute to a switch in the placenta from proliferation to differentiation, thereby improving its nutrient transfer capacity. Upregulation of PPARG and UCP2 would promote placental fatty acid metabolism thereby limiting glucose utilization. These compensatory placental responses may serve to maintain fetal growth but could result in adverse adaptations such as the early onset of the metabolic syndrome in later life.

Reproduction (2009) 138 601-608
\end{abstract}

\section{Introduction}

The placenta's capacity to transport nutrients is essential for the growing fetus and is dependent on its size, morphology, endocrine, and metabolic function (Fowden et al. 2008). Maternal nutrient restriction (NR) during early-to-mid-gestation significantly affects placental growth and morphology (Clarke et al. 1998, Heasman et al. 1998a), causing a reduction in the weight of the fetal component of the placentome (Clarke et al. 1998). At the same time placental sensitivity to glucocorticoids is raised in conjunction with reduced cell proliferation, downregulation of insulin-like growth factor (IGF)1 receptor gene expression while that of uncoupling protein (UCP)2 is upregulated (Gnanalingham et al. 2007). These placental adaptations to maternal NR, would be expected to alter fetal nutrient supply (Fowden et al. 2008) and therefore potentially predispose the offspring to cardiovascular and metabolic health problems in later life (McMillen \& Robinson 2005).

Glucocorticoids play a pivotal role in placento-fetal development, promoting tissue maturation and differentiation (Fowden et al. 1998) and suppressing cell proliferation (Fernandes et al. 1999). Placental sensitivity to glucocorticoids is regulated by the glucocorticoid receptor (GR) together with the activity of the enzyme $11 \beta$-hydroxysteroid dehydrogenase type 2 (HSD11B2) that inactivates cortisol to cortisone (Edwards et al. 1996). IGF2 also has a key role in placental development by regulating proliferation, differentiation, and fetal nutrient supply (Fowden 2003). The action of IGF2 is modulated by both the IGF1 receptor, which promotes the biological activities of IGF2, and the IGF2 receptor, which binds to IGF2 resulting in its intracellular lysosomal degradation (Fowden 2003).

Placental metabolism is primarily dependent on glucose and oxygen availability (Meschia et al. 1980, 
Hay 1995). Following maternal NR, maternal glucose concentrations can be reduced (Heasman et al. 1998a) and plasma non-esterified fatty acids (NEFA) increased (Heasman et al. 1998a, Bispham et al. 2003). While placental transfer of NEFA to the fetus in sheep is normally limited (Hull et al. 1979), when nutrient supply is constrained they may play a role in placental metabolism in conjunction with increased uptake of ketone bodies (Chandler et al. 1985). One factor that could regulate oxidative metabolism in the placenta is the mitochondrial UCP2 by promoting NEFA oxidation in preference to carbohydrate (Pecqueur et al. 2008). Any change in placental metabolism could be further influenced by the action of peroxisome proliferator-activated receptors (PPARs; Nunn et al. 2007) of which PPAR $\gamma$ (PPARG) is highly expressed in the placenta (Schaiff et al. 2006).

Maternal NR between days 28 and 80 of gestation promotes gene expression of both UCP2 and the GR in the placenta, but the extent to which this adaptation may be dependent on the timing of nutritional intervention is unknown. Both epidemiological and animal studies demonstrate that the timing of maternal NR has differential long-term effects on the health of the offspring (Roseboom et al. 2006, Symonds et al. 2007). In this regard, the placenta is an important modulator of the intrauterine environment and has a key role to play in mediating the programming effects of maternal NR (Fowden et al. 2008). Placental development in sheep comprises three distinct critical windows: embryogenenesis occurring within the first 30 days of mating; a period of rapid placental growth with peak weight occurring between days 75 and 80 (Ehrhardt \& Bell 1995); and a period of extensive vascular remodeling and a decline, of up to $30 \%$, in weight for the remainder of the pregnancy (Schneider 1996). We hypothesized that maternal NR during these critical windows would result in differential effects on placental development and metabolism. Specifically, the primary aim of the study was to investigate the effects of maternal NR on modulators of placental growth and nutrient supply. In view of the potential switch in placental metabolism during maternal NR, the secondary aim of the study was to investigate the effects of maternal NR on genes involved in placental lipid metabolism.

\section{Results}

Maternal NR during the specific stages of gestation had no effect on the total weight of the placenta, fetal weight, or the fetal to placenta ratio at day 110 (Table 1). At the end of each period of maternal NR, there was a decline in maternal weight in all groups compared with their body weight at the start of the period of NR with the exception of the group of animals that were nutrient restricted between days 66 and 110 (NR 0-30 days, $-7.2 \pm 2.1 \%, P<0.05$; NR $31-65$ days, $-11.2 \pm 2.0 \%$,
$P<0.05 ;$ NR $0-110$ days, $-24.8 \pm 2.0 \%, P<0.001$ ). However, there was only a significant difference in maternal body weight between conception and day 110 of gestation in those animals nutrient restricted throughout gestation (Table 1).

Proliferating cells within the placenta as determined by proliferating cell nuclear antigen (PCNA) staining indicated these were present in both the maternal caruncular and fetal cotyledon components primarily around the luminal epithelium and glandular endothelium (Fig. 1A-C). Following maternal NR from 66 to 110 days of gestation, placental cell proliferation had decreased in both the maternal caruncular $(P<0.05$, Fig. 1D and $\mathrm{E}$ ) and the fetal cotyledonary components of the placentome (Fig. 1F).

Placental gene expression of the GR was increased only following maternal NR between days 66 and 110 (Fig. 2A) and this was not accompanied by any change in mRNA abundance for HSD11B2 (Fig. 2B). IGF2R (Fig. 2C), PPARG, and UCP2 mRNA abundance were also specifically upregulated following NR between days 66 and 110 (Fig. 3). There was no effect of maternal NR at any time point on gene expression for $I G F 1$, its receptor, or IGF2 (data not shown).

\section{Discussion}

The aim of this study was to investigate the endocrine and metabolic adaptations within the ovine placenta following maternal NR during different critical windows of placento-fetal development. We have, therefore, established that significant effects were only seen when maternal NR commenced at day 66 of gestation and was continued to the end of the study, i.e. day 110 of gestation. This 45-day period of NR reduced placental cell proliferation, without any effect on total placental mass. At the same time, there was an increase in glucocorticoid sensitivity (as indicated by increased GR mRNA abundance), whereas IGF2 activity was suppressed, following upregulation of the IGF2R. These adaptations were accompanied by the upregulation of a number of genes involved in lipid sensing and metabolism. Importantly, placental responses to maternal NR were coincident with the time of maximal placental growth (Ehrhardt \& Bell 1995) and the beginning of the period exponential fetal growth. Such adaptations to NR may be beneficial for the survival of the fetus during a time of high metabolic demands but could alter the intrauterine environment to reset fetal organ growth and predisposing the offspring to metabolic disease in later life (McMillen \& Robinson 2005, Sebert et al. 2009, Sharkey et al. 2009). The comparative importance of our findings is emphasized by the close similarity in the growth curves of the placenta and the fetus between sheep and humans. In both species, placental growth is most rapid between early-to-mid-gestation and is then 
Table 1 The effect of maternal nutrient restriction (NR; 50\% of metabolizable energy) during different gestational windows on maternal, placental, and fetal weights at day 110 of pregnancy in the sheep.

\begin{tabular}{|c|c|c|c|c|c|}
\hline $\begin{array}{l}\text { Maternal nutrient } \\
\text { group (days of gestation } \\
\text { of NR) }\end{array}$ & Control & $0-30$ days & 31-65 days & 66-110 days & 0-110 days \\
\hline $\begin{array}{l}\text { Maternal weight } \\
\text { change }(\%)\end{array}$ & $1.7 \pm 2.2$ & $3.7 \pm 3.1$ & $-1.9 \pm 2.6$ & $-7.2 \pm 0.7$ & $-22.8 \pm 2.0^{*}$ \\
\hline Placental weight (g) & $632 \pm 59$ & $670 \pm 40$ & $636 \pm 38$ & $639 \pm 17$ & $697 \pm 63$ \\
\hline Fetal weight $(\mathrm{g})$ & $2048+57$ & $2198+47$ & $2226+80$ & $2030+41$ & $1961+99$ \\
\hline Fetal/placental ratio & $3.4 \pm 0.4$ & $3.4 \pm 0.2$ & $3.6 \pm 0.2$ & $3.2 \pm 0.1$ & $2.9 \pm 0.3$ \\
\hline
\end{tabular}

Data represents means \pm s.E.M.; $n=4-8$ animals/group. ${ }^{*} P<0.001$ compared to controls. NR, nutrient restriction.

followed by an exponential period of fetal growth in late gestation (Heasman et al. 1998b).

In previous studies, maternal NR during early-to-midgestation (30-80 days) resulted in the reduction of weight of the fetal component, but not the total placenta, immediately after the period of NR (Clarke et al. 1998). Previously, when nutrient-restricted sheep were subsequently fed to requirements from mid-gestation (80 days to term), the weights of the fetal component of the placenta, as well as that of the whole placenta weight, increased compared with adequately fed controls (Clarke et al. 1998, Heasman et al. 1998a). In the present study, we did not detect a difference in the total placental weight following NR at each of the different gestational windows but found a marked loss of cell proliferation throughout the placenta following maternal NR between days 66 and 110. In addition, fetal weight and fetal-to-placental weight ratio, a measure of placental efficiency, were unaffected by any of the periods of maternal NR in the present study. The most probable explanation for the lack of any effect on placental weight in the current study is that not only were the periods of nutritional intervention of shorter duration (with the exception of those mothers who were nutrient restricted through out the entire 110-day study period), but placental sampling was undertaken at day 110 gestation, instead of day 80 and is thus within the period in which the placental weight starts to decline (Stegmann 1974, Ehrhardt \& Bell 1995).
Glucocorticoids are important modulators of placento-fetal growth and excessive exposure during later stages of pregnancy results in a reduction in placental and fetal weight with an overall increase in fetalto-placenta weight ratio (Jensen et al. 2002). Maternal NR between days 66 and 110 increased placental sensitivity to glucocorticoids by upregulation of GR mRNA abundance, but had no effect on HSD11B2 gene expression. By contrast, in previous studies maternal NR during early-to-mid-gestation resulted in a persistent upregulation of GR, whereas the abundance of HSD11B2 mRNA was reduced (Whorwood et al. 2001, Gnanalingham et al. 2007). One factor that appears to determine the magnitude of change in placenta glucocorticoid action following maternal NR is the reduction in plasma cortisol (Whorwood et al. 2001, Jaquiery et al. 2006, Rumball et al. 2008). Consequently, reduced maternal cortisol with NR appears to be amplified in early, but not later, gestation, thereby explaining the absence of any reduction in placental HSD11B2 when food intake is reduced later in gestation. This could also explain the lack of any effect on fetal plasma cortisol with maternal NR, irrespective of its timing (Brameld et al. 2000, Edwards \& McMillen 2001, Jaquiery et al. 2006). The main outcome of increased GR abundance appears to be a suppression of cell proliferation (Fernandes et al. 1999) that in the placenta may act to promote placental remodeling and differentiation (Fowden et al. 1998). It is also established that, in the
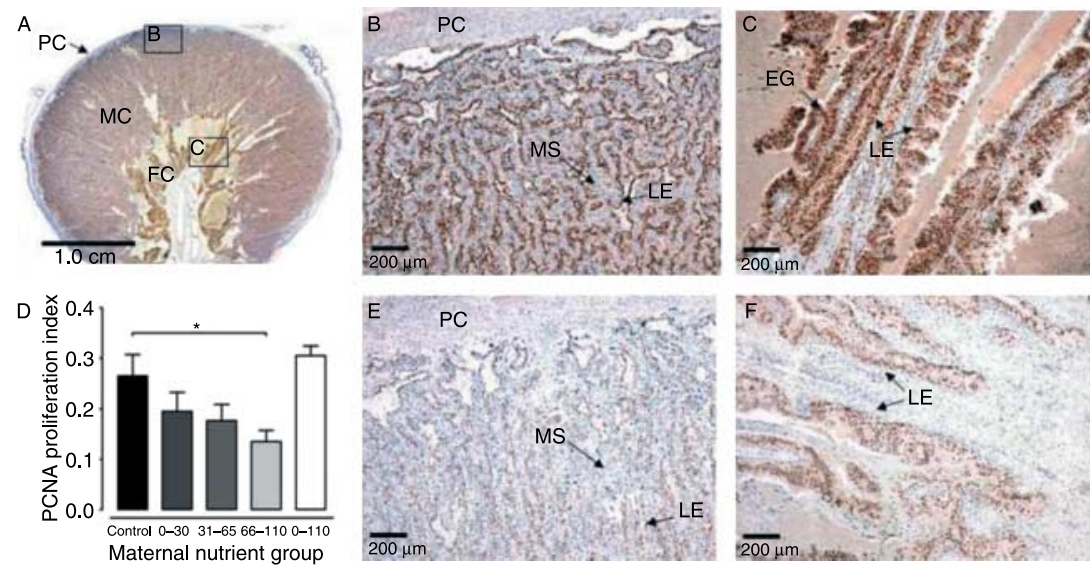

Figure 1 Quantitative immunohistochemistry of proliferating cell nuclear antigen (PCNA) in the ovine placentome. (A-C) PCNA positive nuclei (stained brown) are localized in both the maternal caruncular (MC) and fetal cotyledon (FC) components of the placentome particularly surrounding the maternal luminal epithelium (LE) and endothelial glands (EG). (D) The effect of maternal nutrient restriction during different gestational windows on PCNA expression in the maternal caruncular component of the placentome. (E and F) Representative placentome micrographs $(\times 40)$ from sheep that were nutrient-restricted from 66 to 110 days of gestation. MS, maternal stroma. 

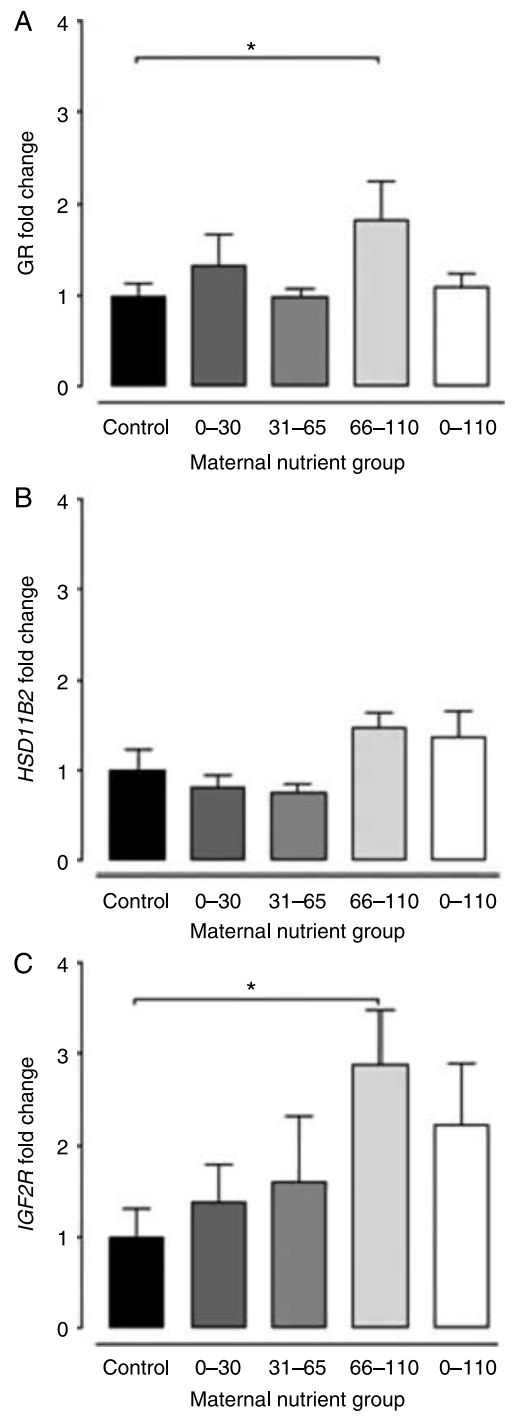

Figure 2 (A) Effect of maternal nutrient restriction at different gestational windows on the mRNA abundance of glucocorticoid receptor (GR);

(B) 11ß-hydroxysteroid dehydrogenase type 2 (HSD11B2); and (C) insulin-like growth 2 receptor (IGF2R), as determined by real-time PCR. Data were expressed relative to the ribosomal 18S RNA and normalized to the control group to give fold change. Data represent means \pm s.E.M. ${ }^{*} P<0.05$.

placenta, gene expression of the GR is positively correlated with UCP2 and may thus be one underlying mechanism by which changes in placental metabolism are mediated (Gnanalingham et al. 2007).

Placental adaptations could be further modulated by changes in IGF action, of which IGF2 is the dominant factor regulating placento-fetal growth (Fowden 2003). During maternal NR, maternal and fetal IGF1 concentrations are either decreased (Bauer et al. 1995, Osgerby et al. 2002, Bispham et al. 2003) or unchanged (Quigley et al. 2008, Sosa et al. 2009), while maternal and fetal IGF2 concentrations remain unchanged (Bauer et al. 1995, Quigley et al. 2008).
We found no effect on placenta IGF1 or 2 mRNA abundance which is in accord with other studies (Osgerby et al. 2002, McMullen et al. 2005). In the present study, NR between days 66 and 110 gestation enhanced IGF2R mRNA abundance, whereas no effect was seen on IGF1R. Gene expression of IGF1R was raised in the fetal kidney in the absence of any difference in kidney weight or nephron number (Brennan et al. 2005). It is, therefore, proposed that these placento-fetal adaptations within the IGF axis could ensure that fetal growth and development are maintained despite a reduction in maternal food intake. The overall placental response to a period of maternal NR commencing later in pregnancy is a switch from cell proliferation to differentiation while placenta nutrient transfer capacity is maintained (Dandrea et al. 2001, Fowden et al. 2006). Of further interest is the absence of any significant effects within the placenta when maternal NR was applied from the time of mating until day 110 of gestation. Taken together, these findings indicate that if the level of food intake is kept constant through pregnancy and the mother is able to meet any energy deficit from mobilization of her own body reserves, placenta responses may not be required. However, an increase
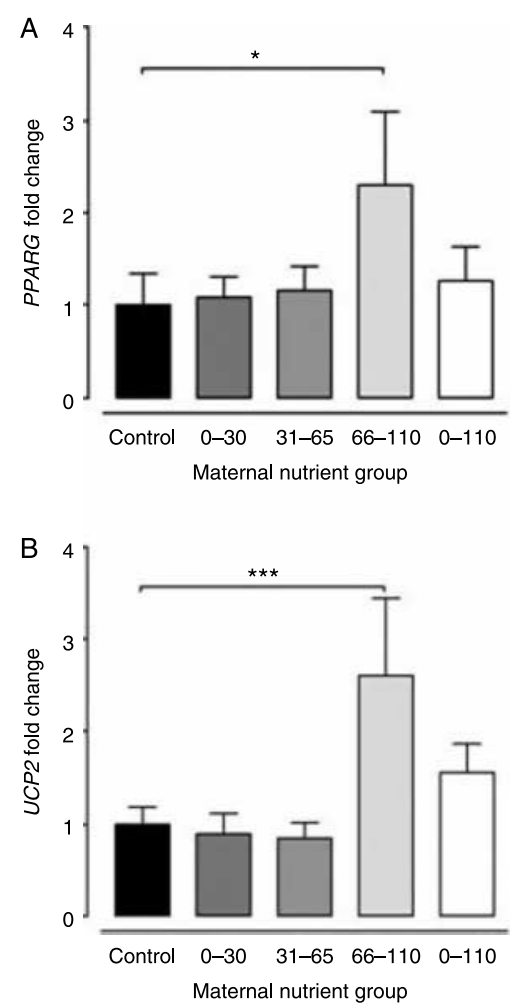

Figure 3 (A) Effect of maternal nutrient restriction during different gestational windows on the mRNA abundance of peroxisome proliferator-activated receptor $\gamma(P P A R G)$; and (B) uncoupling protein (UCP)2, as determined by real-time PCR. Data were expressed relative to ribosomal $18 \mathrm{~S}$ RNA and normalized to the control group to give fold change. Data represent means \pm s.E.M. ${ }^{*} P<0.05,{ }^{* * *} P<0.001$. 
in fetal fat mass is seen in this group (Brennan et al. 2005), that may be indicative of other adaptations within the placento-fetal unit that ultimately contribute to a marked change in adipose tissue function in later life, especially following obesity (Sharkey et al. 2009).

Placenta metabolism is primarily dependant on the availability of oxygen and glucose (Hay 1995). During maternal NR in sheep, maternal glucose concentrations are either unchanged (Edwards \& McMillen 2001, Bispham et al. 2003, Sosa et al. 2009) or reduced (Heasman et al. 1998a, Osgerby et al. 2002, Quigley et al. 2008), whereas plasma NEFA concentrations are consistently raised (Chandler et al. 1985, Bauer et al. 1995, Heasman et al. 1998a, Brameld et al. 2000, Bispham et al. 2003, Quigley et al. 2008, Sosa et al. 2009). Fetal plasma NEFA concentrations, however, remain unchanged (Bauer et al. 1995) as transfer of NEFA across the ovine placenta is limited (Hull et al. 1979). If raised, maternal NEFA were accompanied by reduced utero-placental oxygen uptake (Chandler et al. 1985), this could result in increased production of placental reactive oxidation species as a consequence of enhanced lipid oxidation. In the present study, we found upregulation of both PPARG and UCP2 when NR was specifically targeted from day 66 to 110 of gestation. Both PPARG and UCP2 are involved in lipid sensing and NEFA are the main ligands for PPARs that act to induce UCP expression (Thompson \& Kim 2004). Consequently, because PPARs are transcription factors primarily involved in lipid metabolism and fat deposition for which PPARG has a high abundance within both adipose tissue and the placenta (Alaynick 2008), an increase in gene expression is likely to have important functional consequences. Ultimately, this could have an impact on the partition of nutrient between the placenta and fetus possibly via changes in mitochondrial function (Kliewer et al. 1994).

It is, therefore, possible that as in the murine and human placenta in which PPARG modulates lipid uptake and metabolism (Schaiff et al. 2006) a comparable, and previously over-looked, effect is seen in the sheep placenta. We have previously shown that UCP2 gene expression increases with both gestational age and maternal NR as the metabolic demands from the growing fetus increase (Gnanalingham et al. 2007). Increased action of UCP2 in the placenta during maternal NR could serve to promote mitochondrial fatty acid oxidation while limiting glucose metabolism. UCPs are able to uncouple the oxidation of fatty acids by affecting the electron transport chain from ATP synthesis (Echtay et al. 2000). Fatty acids also affect the expression of UCPs by acting as ligands for PPARs. Indeed, the main products of fatty acid metabolism are acetate and $\beta$-hydroxybutyrate that are readily transferred across the placenta (Hull et al. 1979, Miodovnik et al. 1982). These could therefore be used as an alternative fuel for fetal metabolism and lipogenesis (Herrera 2002).
Clearly, further studies are required to establish the role of lipid metabolism in the sheep placenta following maternal NR and the extent to which this impacts on placento-fetal metabolism.

In conclusion, maternal nutritional manipulation targeted to the time when placenta growth is maximal has the greatest effects on its endocrine function and metabolism, without compromising placental or fetal growth. These adaptations within the placenta are compensatory in nature, include a switch from proliferation to differentiation, and promote fatty acid metabolism. Despite the potential beneficial nature of these placental responses for fetal growth and development, they are likely to contribute to potentially adverse adaptations that would be detrimental to the long-term metabolic health of the offspring (Sebert et al. 2009, Sharkey et al. 2009).

\section{Materials and Methods}

\section{Animals}

A total of 59 mature Scottish Blackface sheep of similar body condition scores (range 2.0-3.0, on a scale of 0-5; Russel 1984) were randomly allocated to one out of five nutritional treatment groups at mating. They were housed individually under normal lighting conditions. At day 80 of gestation, fetal number was determined by ultrasound. Only singletons $(n=30)$ were included in the present study. All sheep had weight and body condition score assessments at regular intervals throughout the study as previously reported (Rae et al. 2001). Pregnant sheep were killed by barbiturate overdose (Euthatal, $500 \mathrm{mg} / \mathrm{ml}$, $30 \mathrm{ml}$ i.v.; Rhone Merieux, Harlow, UK) on day 110 gestation. The total placental mass was calculated by dissecting and weighing individual placentomes. Representative placentomes from each sheep were randomly selected, frozen immediately in liquid nitrogen and stored at $-80{ }^{\circ} \mathrm{C}$ for later analysis. Additional placentomes were dissected and placed into $10 \%$ formalin and embedded in paraffin wax for histological analysis. All experimental procedures had the required Home Office approval as designated by the Animals (Scientific Procedures) Act (1986) and were performed under UK legislation.

\section{Maternal diet}

Sheep were fed diets estimated to provide the metabolizable energy (ME) requirement for live weight maintenance ( $\sim 8.0 \mathrm{M}$ /ME per day) or $50 \%$ of that amount. The diet comprised concentrated pellet feed (Green Keil, Harbro Ltd, Turriff, UK) and hay, with access to water ad libitum. The animals were fed, initially, as follows: control animals $(n=6)$ received $100 \%$ of requirements throughout the study, whereas nutrient restricted groups received 50\% (4.0 MJ/ME per day) of this amount from 0 to $30(n=8), 31$ to $65(n=6)$, 66 to $110(n=4)$, and 0 to $110(n=6)$ days of gestation respectively. From day 80 of gestation, the rations were increased to match the increasing nutrient requirements of 
Table 2 Oligonucleotide primer sequences used for quantification of target and endogenous control gene cDNA by real-time PCR.

\begin{tabular}{lll}
\hline Gene & Primer sequence & \\
\hline $18 S$ & Forward: GAT GCG GCG GCG TTA TTC C & Reverse: CTC CTG GTG GTG CCC TCC C \\
GR & Forward: ACT GCC CCA AGT GAA AAC AGA & Reverse: ATG AAC AGA AAT GGC AGA CAT TTT ATT \\
HSD11B2 & Forward: AGC AGG AGA CAT GCC GTT TC & Reverse: GCA ATG CCA AGG CTG CTT \\
$I G F 1$ & Forward: TCT TAG TCC CTG CCT CTC & Reverse: GCC TGC TGA ATG AAT GTC \\
$I G F 1 R$ & Forward: TCT AAC TTT GTC TTT GCA AGA A & Reverse: TCA CTG GCC CAG GAA ATG TC \\
$I G F 2$ & Forward: TCA CAG CAG GAA AGT CGA TG & Reverse: GGC ACA GTA AGT CTC CAG CA \\
$I G F 2 R$ & Forward: GAG ACT CCT TGT TCT ACA CTT CGG & Reverse: CGG GCA CTT GGC TTC CTC \\
PPARG & Forward: ACG GGA AAG ACG ACA GAC AAA & Reverse: GAC GGA GCG AAA CTG ACA CC \\
UCP2 & Forward: ATG ACA GAC GAC CTC CCT TG & Reverse: GGG CAT GAA CCC TTT GTA GA \\
\hline
\end{tabular}

18S, 18 S ribosomal RNA; GR, glucocorticoid receptor; HSD11B2, $11 \beta$ hydroxysteroid dehydrogenase type 2; IGF, insulin-like growth factor; $\mathrm{R}$, receptor; PPARG, peroxisome proliferator-activated receptor $\gamma$; UCP, uncoupling protein.

the developing fetuses (Robinson et al. 1983). Fetal gender was determined at delivery and was as follows: controls (three males and three females); NR 0-30 days (four males and four females); NR 31-65 days (four males and two females); NR 66-110 days (two males and two females); NR 0-110 days (two males and four females).

\section{PCNA staining}

Cell proliferation was determined by immunoreactive PCNA expression (Waseem \& Lane 1990). Placentome sections $(5 \mu \mathrm{m})$ were stained with PCNA-specific antibody using a mouse MAB to PCNA (PC10) (Alexis Biochemicals, Nottingham, UK) at a 1:200 dilution. Immunohistochemical analysis was performed on a computerized bond automated immunohistochemistry system (Leica Biosystems Ltd, Newcastle-uponTyne, UK) using a bond polymer refine detection kit. At the end of the automated immunostaining, the sections were dehydrated in alcohol and xylene and mounted in resinous medium. Image acquisition was carried out using a Nikon Eclipse 90i microscope and camera Micropublisher 3.3 RTM (Q imaging, Surrey, BC, Canada). Volocity Acquisition and Quantification Software (Version 4.2.1, Improvision Ltd, Coventry, UK) was used for image analysis. A total of 10 fields from each section were randomly selected from the maternal caruncular section of the placentome and photographed at $\times 100$ magnification $\left(0.370277 \mathrm{~mm}^{2}\right.$ per field). Positive (brown) and negative (blue) cells were identified by the software using red-green-blue ranges. The index of cell proliferation was assessed as a ratio of positively stained cells over total number of cells per field (Correia-da-Silva et al. 2004).

\section{mRNA analysis}

Total RNA was extracted from $100 \mathrm{mg}$ of maternal caruncular placentome tissue using Qiazol lysis reagent and RNeasy extraction kit (Qiagen). RNA was treated with DNAse I digestion using RNase-free DNase set (Qiagen). Two microgram RNA was used to generate $20 \mu \mathrm{l}$ cDNA using 200 units of Superscript II reverse transcriptase (Invitrogen Ltd) and $125 \mathrm{ng}$ random primers (GE Healthcare Life Sciences, Amersham, UK) according to the enzyme manufacturer's guidelines. Negative control RT samples lacking Superscript II $(-R T)$ were included for each sample. We performed real-time PCR using $15 \mu \mathrm{l}$ reactions consisting of $4.5 \mu \mathrm{l}$ diluted 1:10 cDNA, $3.0 \mu \mathrm{l}$ (final concentration of $250 \mathrm{nM}$ ) gene specific primers (Table 2, Sigma-Aldrich), and $7.5 \mu$ SYBR Green mastermix (Qiagen). Duplicate samples were run for 40 cycles with negative controls in 96-well plates using the Techne Quantica thermocycler (Techne Inc., Barloword Scientific, Stone, UK). 10-fold serial dilutions of cDNA for each gene were used to generate standard curve analysis and only experiments with $R^{2}>0.985$ were included. $18 \mathrm{~S}$ ribosomal RNA was used as a housekeeping gene and relative mRNA expression was calculated by $2^{-\Delta C_{\mathrm{t}}}$ method (Livak \& Schmittgen 2001). Data for each NR group were expressed as a ratio to the control animals.

\section{Statistical analysis}

All statistical evaluations were performed by using SPSS 15.0 for Windows (SPSS Inc., Chicago, IL, USA). Maternal NR effects were assessed using general linear model multivariate analysis with least significant difference post hoc tests. The study was not designed or powered to look at the effect of fetal gender on the placenta and this was analyzed as a covariate. All values presented are means with their standard errors. $P$ value $<0.05$ was deemed to represent statistical significance.

\section{Declaration of interest}

None of the authors have any interest to declare.

\section{Funding}

The research was funded by the European Union Sixth Framework for Research and Technical Development of the European Community - The Early Nutrition Programming Project (FOOD-CT-2005-007036), the Institute of Clinical Research, University of Nottingham and the Rural Environment Research and Analysis Department of the Scottish Government.

\section{References}

Alaynick WA 2008 Nuclear receptors, mitochondria and lipid metabolism. Mitochondrion 8 329-337.

Bauer MK, Breier BH, Harding J, Veldhuis JD \& Gluckman PD 1995 The fetal somatotrophic axis during long term maternal undernutrition in sheep; evidence of nutritional regulation in utero. Endocrinology 136 $1250-1257$. 
Bispham J, Gopalakrishnan G, Dandrea J, Wilson V, Budge H, Keisler D, Broughton Pipkin F, Stephenson T \& Symonds M 2003 Maternal endocrine adaptation throughout pregnancy to nutritional manipulation: consequences for maternal plasma leptin and cortisol and the programming of fetal adipose tissue development. Endocrinology 144 3575-3585.

Brameld JM, Mostyn A, Dandrea J, Stephenson TJ, Dawson JM, Buttery PJ \& Symonds ME 2000 Maternal nutrition alters the expression of insulinlike growth factors in fetal sheep liver and skeletal muscle. Journal of Endocrinology 167 429-437.

Brennan KA, Gopalakrishnan GS, Kurlak L, Rhind SM, Kyle CE, Brooks AN, Rae MT, Olson DM, Stephenson T \& Symonds ME 2005 Impact of maternal undernutrition and fetal number on glucocorticoid, growth hormone and insulin-like growth factor receptor mRNA abundance in the ovine fetal kidney. Reproduction 129 151-159.

Chandler KD, Leury BJ, Bird AR \& Bell AW 1985 Effects of undernutrition and exercise during late pregnancy on uterine, fetal and uteroplacental metabolism in the ewe. British Journal of Nutrition 53 625-635.

Clarke L, Heasman L, Juniper D \& Symonds M 1998 Maternal nutrition in early-mid gestation and placental size in sheep. British Journal of Nutrition 79 359-364.

Correia-da-Silva G, Bell S, Pringle J \& Teixeira N 2004 Patterns of uterine cellular proliferation and apoptosis in the implantation site of the rat during pregnancy. Placenta 25 538-547.

Dandrea J, Wilson V, Gopalakrishnan G, Heasman L, Budge H, Stephenson T \& Symonds ME 2001 Maternal nutritional manipulation of placental growth and glucose transporter-1 abundance in sheep. Reproduction 122 793-800.

Echtay KS, Winkler E \& Klingenberg M 2000 Coenzyme Q is an obligatory cofactor for uncoupling protein function. Nature 408 609-613.

Edwards LJ \& McMillen IC 2001 Maternal undernutrition increases arterial blood pressure in the sheep fetus during late gestation. Journal of Physiology 533 561-570.

Edwards CR, Benediktsson R, Lindsay RS \& SeckI JR 1996 11ßHydroxysteroid dehydrogenases: key enzymes in determining tissuespecific glucocorticoid effects. Steroids 61 263-269.

Ehrhardt RA \& Bell AW 1995 Growth and metabolism of the ovine placenta during mid-gestation. Placenta 16 727-741.

Fernandes D, Guida E, Koutsoubos V, Harris T, Vadiveloo P, Wilson JW \& Stewart AG 1999 Glucocorticoids inhibit proliferation, cyclin D1 expression, and retinoblastoma protein phosphorylation, but not activity of the extracellular-regulated kinases in human cultured airway smooth muscle. American Journal of Respiratory Cell and Molecular Biology 21 77-88.

Fowden AL 2003 The insulin-like growth factors and feto-placental growth. Placenta 24 803-812.

Fowden AL, Li J \& Forhead AJ 1998 Glucocorticoids and the preparation for life after birth: are there long-term consequences of the life insurance? Proceedings of the Nutrition Society 57 113-122.

Fowden AL, Ward JW, Wooding FP, Forhead AJ \& Constancia M 2006 Programming placental nutrient transport capacity. Journal of Physiology $5725-15$.

Fowden AL, Forhead AJ, Coan PM \& Burton GJ 2008 The placenta and intrauterine programming. Journal of Neuroendocrinology 20 439-450.

Gnanalingham MG, Williams P, Wilson V, Bispham J, Hyatt MA, Pellicano A, Budge H, Stephenson T \& Symonds ME 2007 Nutritional manipulation between early to mid-gestation: effects on uncoupling protein-2, glucocorticoid sensitivity, IGF-I receptor and cell proliferation but not apoptosis in the ovine placenta. Reproduction 134 615-623.

Hay WW 1995 Current topic: metabolic interrelationships of placenta and fetus. Placenta 16 19-30.

Heasman L, Clarke L, Firth K, Stephenson T \& Symonds M 1998a Influence of restricted maternal nutrition in early to mid gestation on placental and fetal development at term in sheep. Pediatric Research 44 546-551.

Heasman L, Clarke L, Dandrea J, Stephenson T \& Symonds ME $1998 b$ Correlation of fetal number with placental mass in sheep. Contemporary Reviews in Obstetrics and Gynaecology 10 275-280.

Herrera E 2002 Implications of dietary fatty acids during pregnancy on placental, fetal and postnatal development - a review. Placenta 23 S9-S19.
Hull D, Elphick MC \& Broughton Pipkin F 1979 The transfer of fatty acids across the sheep placenta. Journal of Developmental Physiology $\mathbf{1}$ $31-45$.

Jaquiery AL, Oliver MH, Bloomfield FH, Connor KL, Challis JR \& Harding JE 2006 Fetal exposure to excess glucocorticoid is unlikely to explain the effects of periconceptional undernutrition in sheep. Journal of Physiology 572 109-118.

Jensen EC, Gallaher BW, Breier BH \& Harding JE 2002 The effect of a chronic maternal cortisol infusion on the late-gestation fetal sheep. Journal of Endocrinology 174 27-36.

Kliewer SA, Forman BM, Blumberg B, Ong ES, Borgmeyer U, Mangelsdorf DJ, Umesono K \& Evans RM 1994 Differential expression and activation of a family of murine peroxisome proliferator-activated receptors. PNAS 91 7355-7359.

Livak K \& Schmittgen T 2001 Analysis of relative gene expression data using real-time quantitative PCR and the 2(-Delta Delta $C(\mathrm{~T})$ ) method. Methods 25 402-408.

McMillen IC \& Robinson JS 2005 Developmental origins of the metabolic syndrome: prediction, plasticity, and programming. Physiological Reviews 85 571-633.

McMullen S, Osgerby JC, Milne JS, Wallace JM \& Wathes DC 2005 The effects of acute nutrient restriction in the mid-gestational ewe on maternal and fetal nutrient status, the expression of placental growth factors and fetal growth. Placenta 26 25-33.

Meschia G, Battaglia FC, Hay WW \& Sparks JW 1980 Utilization of substrates by the ovine placenta. Federation Proceedings 39 245-249.

Miodovnik M, Lavin JP, Harrington DJ, Leung LS, Seeds AE \& Clark KE 1982 Effect of maternal ketoacidemia on the pregnant ewe and the fetus. American Journal of Obstetrics and Gynecology 144 585-593.

Nunn AV, Bell J \& Barter P 2007 The integration of lipid-sensing and antiinflammatory effects: how the PPARs play a role in metabolic balance. Nuclear Receptor 51.

Osgerby JC, Wathes DC, Howard D \& Gadd TS 2002 The effect of maternal undernutrition on fetal growth. Journal of Endocrinology 173 131-141.

Pecqueur C, Bui T, Gelly C, Hauchard J, Barbot C, Bouillaud F, Ricquier D, Miroux B \& Thompson CB 2008 Uncoupling protein-2 controls proliferation by promoting fatty acid oxidation and limiting glycolysisderived pyruvate utilization. FASEB Journal 22 9-18.

Quigley SP, Kleemann DO, Walker SK, Speck PA, Rudiger SR, Nattrass GS, DeBlasio MJ \& Owens JA 2008 Effect of variable long-term maternal feed allowance on the development of the ovine placenta and fetus. Placenta 29 539-548.

Rae M, Palassio S, Kyle C, Brooks A, Lea R, Miller D \& Rhind S 2001 Effect of maternal undernutrition during pregnancy on early ovarian development and subsequent follicular development in sheep fetuses. Reproduction 122 915-922.

Robinson JJ, Russel AFF, Treacher TT \& Kilkenny JB 1983 In Feeding the Ewe, pp 1-60. Milton Keynes: Meat and Livestock Commission Sheep Improvement Services.

Roseboom T, de Rooij S \& Painter R 2006 The Dutch famine and its longterm consequences for adult health. Early Human Development 82 485-491.

Rumball CW, Harding JE, Oliver MH \& Bloomfield FH 2008 Effects of twin pregnancy and periconceptional undernutrition on maternal metabolism, fetal growth and glucose-insulin axis function in ovine pregnancy. Journal of Physiology 586 1399-1411.

Russel A 1984 Body condition scoring of sheep. In Practice 6 91-93.

Schaiff WT, Barak Y \& Sadovsky Y 2006 The pleiotropic function of PPAR gamma in the placenta. Molecular and Cellular Endocrinology 249 10-15.

Schneider H 1996 Ontogenic changes in the nutritive function of the placenta. Placenta 17 15-26.

Sebert SP, Hyatt MA, Chan LL, Patel N, Bell RC, Keisler D, Stephenson T, Budge H, Symonds ME \& Gardner DS 2009 Maternal nutrient restriction between early-to-mid gestation and its impact upon appetite regulation following juvenile obesity. Endocrinology 150 634-641.

Sharkey D, Gardner DS, Fainberg HP, Wilson V, Sebert S, Bos P, Bell R, Symonds ME \& Budge H 2009 Maternal nutrient restriction during pregnancy differentially alters the unfolded protein response in adipose and renal tissue of obese juvenile offspring. FASEB Journal 23 1314-1324. 
Sosa C, Abecia JA, Carriquiry M, Forcada F, Martin GB, Palacin I \& Meikle A 2009 Early pregnancy alters the metabolic responses to restricted nutrition in sheep. Domestic Animal Endocrinology 36 13-23.

Stegmann JHJ 1974 Placental development in sheep. Bijdragen Tot de Dierkunde 44 4-72.

Symonds M, Stephenson T, Gardner D \& Budge H 2007 Long-term effects of nutritional programming of the embryo and fetus: mechanisms and critical windows. Reproduction Fertility and Development 19 53-63.

Thompson MP \& Kim D 2004 Links between fatty acids and expression of UCP2 and UCP3 mRNAs. FEBS Letters 568 4-9.

Waseem N \& Lane D 1990 Monoclonal antibody analysis of the proliferating cell nuclear antigen (PCNA). Structural conservation and the detection of a nuclear form. Journal of Cell Science 96 121-129.
Whorwood CB, Firth KM, Budge H \& Symonds ME 2001 Maternal undernutrition during early- to mid-gestation programmes tissue-specific alterations in the expression of the glucocorticoid receptor, $11 \beta$ hydroxysteroid dehydrogenase isoforms and type 1 angiotensin II receptor in neonatal sheep. Endocrinology 142 1778-1785.

Received 10 February 2009

First decision 10 March 2009

Revised manuscript received 18 May 2009

Accepted 12 June 2009 